\title{
Caffeine administration modulates TGF- $\beta$ signaling but does not attenuate blunted alveolarization in a hyperoxia-based mouse model of bronchopulmonary dysplasia
}

\author{
Philipp Rath 1,2, Claudio Nardiello ',3, David E. Surate Solaligue 1,3, Ronald Agius ${ }^{4}$, Ivana Mižíková1,3, Sebastian Hühn², \\ Konstantin Mayer ${ }^{3}$, István Vadász ${ }^{3}$, Susanne Herold ${ }^{3}$, Frank Runkel ${ }^{2,5}$, Werner Seeger ${ }^{1,3}$ and Rory E. Morty ${ }^{1,3}$
}

BACKGROUND: Caffeine is widely used to manage apnea of prematurity, and reduces the incidence of bronchopulmonary dysplasia (BPD). Deregulated transforming growth factor (TGF)- $\beta$ signaling underlies arrested postnatal lung maturation in BPD. It is unclear whether caffeine impacts TGF- $\beta$ signaling or postnatal lung development in affected lungs.

METHODS: The impact of caffeine on TGF- $\beta$ signaling in primary mouse lung fibroblasts and alveolar epithelial type ॥ cells was assessed in vitro. The effects of caffeine administration ( $25 \mathrm{mg} / \mathrm{kg} / \mathrm{d}$ for the first $14 \mathrm{~d}$ of postnatal life) on aberrant lung development and TGF- $\beta$ signaling in vivo was assessed in a hyperoxia $\left(85 \% \mathrm{O}_{2}\right)$-based model of BPD in C57BL/6 mice.

RESULTS: Caffeine downregulated expression of type I and type III TGF- $\beta$ receptors, and Smad2; and potentiated TGF- $\beta$ signaling in vitro. In vivo, caffeine administration normalized body mass under hyperoxic conditions, and normalized Smad2 phosphorylation detected in lung homogenates; however, caffeine administration neither improved nor worsened lung structure in hyperoxia-exposed mice, in which postnatal lung maturation was blunted.

CONCLUSION: Caffeine modulated TGF- $\beta$ signaling in vitro and in vivo. Caffeine administration was well-tolerated by newborn mice, but did not influence the course of blunted postnatal lung maturation in a hyperoxia-based experimental mouse model of BPD.

C affeine is a member of the methylxanthine class of central nervous system stimulants, which along with aminophylline and theophylline are nonspecific antagonists of the adenosine receptor (at low concentrations) and inhibitors of phosphodiesterases (at higher concentrations). Aminophylline was proposed for the treatment of Cheyne-Stokes respiration by the Austrian physician Alfred Vogl in 1927 (1) and was first used to treat apnea of prematurity in 1973 (2), which remains the indication for caffeine administration in a neonatal intensive care setting. Since then, the utility of caffeine in preterm infants has been the subject of intense study, due to the lower toxicity of caffeine compared with other methylxanthines (3). Aranda et al. (4) first administered caffeine for apnea of prematurity in 1977, and this idea culminated in the Caffeine for Apnea of Prematurity (CAP) trial, where caffeine therapy initiated during the first $10 \mathrm{~d}$ of life decreased the incidence of bronchopulmonary dysplasia (BPD) and decreased the duration of mechanical ventilation in infants weighing 500-1,250 g at birth (5). The major reason that caffeine reduces BPD is by reducing apnea and increasing respiratory drive, thereby reducing ventilation-induced lung injury (5). Subsequent studies have highlighted that caffeine therapy also leads to improved long-term neurodevelopmental outcome in affected patients (6), and that the timing of caffeine therapy was important, where early initiation of caffeine therapy (within the first $3 \mathrm{~d}$ of life) may be of more benefit than late caffeine therapy (7).

The ability of caffeine to influence the course of aberrant lung development that occurs in patients with BPD is less well understood (8). Blunted secondary septation leading to an arrest of alveolar development is a histopathological characteristic of the lungs of infants with BPD. Thus, it is of interest to know whether caffeine may impact postnatal lung maturation in general, and alveolarization in particular. It has been demonstrated in vitro that caffeine has concentration-dependent effect on cell-cycle progression and cell viability in MLE- 12 mouse lung and A549 human lung epithelial cell-lines, in the background of hyperoxia (9). Furthermore, in vivo, caffeine application to newborn $\mathrm{FVB} / \mathrm{n}$ mice worsened lung hypoplasia in a hyperoxia-based model of BPD, and this was accompanied by increased epithelial cell apoptosis, and loss of alveolar type II (ATII) cells (10). These two reports indicated a deleterious impact of caffeine in BPD animal models. In contrast, caffeine application to 6-d old rats blunted the inflammatory response provoked by hyperoxia, limiting proinflammatory cytokine expression and inflammatory cell infiltration into the lung (11). This study thus indicated a potential benefit of caffeine application in experimental BPD; however, lung structure was

\footnotetext{
'Department of Lung Development and Remodelling, Max Planck Institute for Heart and Lung Research, Bad Nauheim, Germany; ${ }^{2}$ nstitute of Bioprocess Engineering and Pharmaceutical Technology, Technische Hochschule Mittelhessen-University of Applied Sciences, Giessen, Germany; ${ }^{3}$ Department of Internal Medicine (Pulmonology), University of Giessen and Marburg Lung Center (UGMLC), member of the German Center for Lung Research (DZL), Giessen, Germany; ${ }^{4}$ Department of Forensic and Clinical Toxicology, Labor Krone, Bad Salzuflen, Germany; ${ }^{5}$ Faculty of Biology and Chemistry, Justus Liebig University, Giessen, Germany. Correspondence: Rory E. Morty (rory.morty@mpi-bn.mpg.de) Received 15 August 2016; accepted 27 November 2016; advance online publication 5 April 2017. doi:10.1038/pr.2017.21
} 
not quantified in that study. A beneficial impact of caffeine on experimental BPD has also been demonstrated in preterm rabbits delivered by caesarian section on gestational day 28 , where caffeine administration blunted inflammation and perturbations to lung development provoked by hyperoxia, and improved lung function (12). Thus, current reports are conflicted in an assessment of whether caffeine administration may promote or inhibit postnatal lung maturation.

To date, studies have largely addressed the ability of caffeine to impact inflammation or cell death: two components of the pathological picture of clinical and experimental BPD. To further develop this idea, we elected to examine the impact of caffeine on signaling by the transforming growth factor (TGF)- $\beta$ family of growth factors, which are accredited with a key role in normal and aberrant lung development, where TGF- $\beta$ signaling is pathogenic in BPD. This idea is supported by reports of others that caffeine modulates TGF- $\beta$ signaling in the A549 human lung epithelial cell-line (13). Additionally, we set out to examine the impact of caffeine administration in a BPD mouse model, using state-of-the-art unbiased stereology which can detect changes in total number of alveoli in the lung, and changes in the thickness of the septal wall, with very high precision. These studies contribute valuable data to the question of whether caffeine influences postnatal lung growth in animal models of BPD: an area of experimental neonatal medicine where little consensus currently exists.

\section{METHODS}

Approvals for Studies with Experimental Animals

All animal procedures were approved by the local authorities, the Regierungspräsidium Darmstadt (approval number B2/1236).

\section{Mouse Model of BPD}

The hyperoxia-based model of BPD in mice was described previously (14-16). Newborn C57BL/6 mice were randomized to equal-sized litters (7 pups per litter), and placed in either a normoxic $\left(21 \% \mathrm{O}_{2}\right)$ or hyperoxic $\left(85 \% \mathrm{O}_{2}\right)$ environment within $2 \mathrm{~h}$ of birth. Nursing dams were rotated every $24 \mathrm{~h}$ to limit oxygen toxicity, and received food ad libitum. Pups were killed at P14, with an overdose of sodium pentobarbital (500 mg/kg, intraperitoneal (i.p.); Euthoadorm, CP-Pharma, Burgdorf, Germany), followed by thoracotomy and lung extraction.

\section{Caffeine Administration to Mice}

Caffeine (Sigma, St. Louis, MO) was dissolved in $0.9 \%$ (mass/vol.) $\mathrm{NaCl}$ (Ecoflac Plus infusion solution; B. Braun, Melsungen, Germany). The normoxia and hyperoxia groups of mouse pups were each subdivided into two groups, one of which received caffeine $(25 \mathrm{mg} / \mathrm{kg} / \mathrm{d}$, via i.p. injection), while a second group, the vehicle control group received $0.9 \% \mathrm{NaCl}$ (via i.p. injection) in the same injection volume. Caffeine was administered daily, for $13 \mathrm{~d}$, and pups were killed on P14. From each group, two pups were harvested $1 \mathrm{~h}$ after the first injection, and another two pups were harvested $2 \mathrm{~h}$ after the first injection; to assess caffeine delivery to the lung. At P14, the conclusion of the study, five pups were harvested for stereological analysis of lung structure, and a further five pups were harvested for lung protein and RNA analysis.

\section{Cell Culture}

Primary mouse lung fibroblasts were isolated as described previously (16), and maintained in Dulbecco's modified essential medium (DMEM; GIBCO, Waltham, MA) supplemented with $10 \%$ (vol./vol.) fetal calf serum (FCS) (GIBCO; 10082) and 1\% (mass/vol) penicillinstreptomycin (GE Healthcare, South Logan, UT). Primary mouse lung ATII cells were isolated as described previously (14), and maintained on an air-liquid interface in on transwell supports (Corning Transwell polyester membrane cell culture inserts; $24 \mathrm{~mm}$ transwell with $0.4 \mu \mathrm{m}$ pore polyester membrane insert; Corning, New York, NY) in DMEM (GIBCO) supplemented with 10\% (vol./vol.) FCS and 1\% (mass/vol.) penicillin-streptomycin. For caffeine and TGF $\beta 1$ treatments: cells were incubated for $48 \mathrm{~h}$ in the presence of $1 \mathrm{mmol} / \mathrm{l}$ caffeine (or $\mathrm{NaCl}$ vehicle alone), after which, cells were stimulated with TGF $\beta 1$ ligand (10 ng/ml; R\&D Systems, Wiesbaden, Germany) (or vehicle alone, $0.1 \%$ (mass/vol.) Bovine serum albumin (BSA) in $4 \mathrm{mmol} / \mathrm{l} \mathrm{HCl} ; 1$ : 1,000 dilution in cell culture medium) either for $30 \mathrm{~min}$ (for Smad phosphorylation studies) or $24 \mathrm{~h}$ (for gene expression studies).

\section{Protein Isolation and Immunoblotting}

Protein extracts were prepared from mouse lung tissue and cultured cells as described previously (16). The following antibodies were employed: anti-TGF $\beta R 1$ (Santa Cruz Biotechnology, Santa Cruz, CA; 1 : 1,000); anti-TGFßR2 (Abcam, Cambridge, UK; $1: 500$ ); and anti-TGFßR3 $(1: 100)$, anti-total-Smad2/3 $(1: 1,000)$, anti-phosphoSmad2 (phospho-Smad2 Ser465/467; $1: 1,000)$, anti- $\beta$-actin (1 : 1,000) (all from Cell Signaling, Cambridge, UK). Immune complexes were detected with goat-antirabbit IgG conjugated to horseradish peroxidase (ThermoScientific, Waltham, MA; $1: 6,000$ ) by enhanced chemiluminescence (SuperSignalWest Femto Maximum Sensitivity Substrate; ThermoScientific).

\section{RNA Isolation and Real-time RT-PCR}

Total lung RNA and total RNA from cultured cells was isolated as describe previously (16). Real-time RT-PCR analysis was undertaken as described previously $(16,17)$ using the primers listed in Table 1.

\section{Quantitative Determination of Caffeine in Mouse Lung Tissue}

Lung tissue was homogenized in $500 \mu \mathrm{l}$ of Nuclease-Free Water (Ambion, Waltham, MA). Caffeine levels were quantified by a standard clinical chemistry analysis (18). Briefly, samples were prepared by combining $200 \mu \mathrm{l}$ sample with $280 \mu \mathrm{l}$ acetonitrile, after $5 \mathrm{~min}$, samples were clarified by centrifugation $(14,000 g)$, and $800 \mu$ l clarified sample was diluted with potassium phosphate buffer, and a $30 \mu \mathrm{l}$ aliquot was resolved by reverse-phase high performance liquid chromatography (HPLC) using a Macherey Nagel LiChrospher 100 RP 8 ec CC guard column (Fischer Scientific, Nidderau, Germany) followed by a Macherey Nagel LiChrospher 100 RP 8 EC analytical HPLC column (Fischer Scientific). Sample concentrations were inferred from a five-point calibration consisting of 2, 5, 10, 25, and $50 \mathrm{mg} / \mathrm{l}$ caffeine.

\section{Design-Based Stereology}

All methods employed for the analysis of lung structure were based on American Thoracic Society/European Respiratory Society recommendations for quantitative assessment of lung structure (19). The protocol employed for the design-based stereological analysis of neonatal mouse lungs has been described in the detail previously $(14,15,20)$. Mouse lungs were instillation-fixed through a tracheal cannula at a hydrostatic pressure of $20 \mathrm{cmH}_{2} \mathrm{O}$ with paraformaldehyde/glutaraldehyde, and lung volume determined by the Cavalieri method using the STEPanizer tool (21), prior to treatment with osmium, and uranium to preserve lung structure and minimize artefactual changes to lung structure, such as shrinkage, as described previously $(14,15,20)$. Lungs were embedded in glycol methacrylate resin, and processed for stereological analysis of lung structure, exactly as described previously $(14,15,20)$, using the NewCast PLUS computer-assisted stereology system (Visiopharm, Hoersholm, Denmark). Parameters analyzed included the mean linear intercept (MLI), alveolar septal wall thickness $(\tau)$, total surface area $(S)$, as well as alveolar number $(N)$, and alveolar density $\left(N_{v}\right)$, as described previously $(14,15,20)$. The coefficient of error $(C E)$, the coefficient of variation $(C V)$, as well as the squared ratio between both $\left(C E^{2} / C V^{2}\right)$ were measured for each stereological parameter (Table 2), and the quotient threshold was set at 0.5 to validate the precision of the measurements.

\section{Sex Genotyping of Mice}

Sex determination of mouse pups was performed using the male-specific Sry locus and the sex-independent $I l 3$ gene, as described previously (22).

\section{Statistical Analysis}

Data are presented as mean \pm SD. Differences between groups were evaluated by one-way ANOVA with Tukey's post hoc test for multiple 
Table 1. Primers used for gene expression analysis and sex genotyping

\begin{tabular}{|c|c|c|}
\hline Description & Direction & Sequence \\
\hline \multicolumn{3}{|c|}{ Real-time PCR } \\
\hline \multirow[t]{2}{*}{ TGF $\beta$ R1 } & Forward & 5'-CAGAGGGCACCACCTTAAA-3' \\
\hline & Reverse & 5'-AATGGTCCTGGAAGTTC-3' \\
\hline \multirow[t]{2}{*}{ TGF $\beta R 2$} & Forward & 5'-CCAAGATGCCCATTGTTCACA-3' \\
\hline & Reverse & 5'-CATCCTGGATTCTAGAACTTC-3' \\
\hline \multirow[t]{2}{*}{ TGF $\beta$ R3 } & Forward & 5'-ATGGCAGTGACATCCCACCACAT-3' \\
\hline & Reverse & 5'-AGAACGGTGAAGCTCTCCATCA-3' \\
\hline \multirow[t]{2}{*}{ TGF $\beta 1$} & Forward & 5'-CAGCACGGCCCCAATGTAT-3' \\
\hline & Reverse & 5'-GGGACCTTTTCATATCCAGGACA-3' \\
\hline \multirow[t]{2}{*}{ TGF $\beta 2$} & Forward & 5'-CGAAGAGCTCGAGGCGAGATT-3' \\
\hline & Reverse & 5'-GGCTGGACTGTTGTGACTCCA-3' \\
\hline \multirow[t]{2}{*}{ TGF $\beta 3$} & Forward & 5'-ATTGACTTCCGGCAGGATCTA-3' \\
\hline & Reverse & 5'-CCTCTGGGTTCAGGGTGTTGTA-3' \\
\hline \multirow[t]{2}{*}{ PAI-1 } & Forward & 5'-TTCAGCCCTTGCTTGCCTC-3' \\
\hline & Reverse & 5'-ACACTTTTACTCCGAAGTCGGT-3' \\
\hline \multirow[t]{2}{*}{ CTGF } & Forward & 5'-GGGCCTCTTCTGCGATTTC-3' \\
\hline & Reverse & 5'-ATCCAGGCAAGTGCATTGGTA-3' \\
\hline \multirow[t]{2}{*}{ Smad2 } & Forward & 5'-AAGCCATCACCACTCAGAATTG-3' \\
\hline & Reverse & 5'-CACTGATCTACCGTATTTGCTGT-3' \\
\hline \multirow[t]{2}{*}{ Smad3 } & Forward & 5'-AGGGGCTCCCTCACGTTATC-3' \\
\hline & Reverse & 5'-CATGGCCCGTAATTCATGGTG-3' \\
\hline \multirow[t]{2}{*}{ Smad7 } & Forward & 5'-GGCCGGATCTCAGGCATTC-3' \\
\hline & Reverse & 5'-TTGGGTATCTGGAGTAAGGAGG-3' \\
\hline \multirow[t]{2}{*}{ Polr2a } & Forward & 5'-CTAAGGGGCAGCCAAAGAAAC-3' \\
\hline & Reverse & 5'-CCATTCAGCATACAACTCTAGGC-3' \\
\hline \multicolumn{3}{|l|}{ Genotyping } \\
\hline \multirow[t]{2}{*}{ Sry } & Forward & 5'-TGGGACTGGTGACAATTGTC-3' \\
\hline & Reverse & 5'-GAGTACAGGTGTGCAGCTCT-3' \\
\hline \multirow[t]{2}{*}{ IL3 } & Forward & 5'-GGGACTCCAAGCTTCAATCA-3' \\
\hline & Reverse & 5'-TGGAGGAGGAAGAAAAGCAA-3' \\
\hline
\end{tabular}

(more than two) comparisons, while two-group comparisons were performed with an unpaired Student's $t$-test. All statistical analyses were performed with GraphPad Prism 6.0. The presence of statistical outliers was tested by Grubbs' test, and outliers were removed from all analyses.

\section{RESULTS}

\section{Effects of Caffeine on TGF- $\beta$ Signaling in Primary Cells from Mouse Lungs}

During dose range-finding studies, both primary mouse lung fibroblasts and primary mouse lung alveolar type II (ATII) epithelial cells tolerated $1 \mathrm{mmol} / \mathrm{l}$ caffeine. A higher caffeine concentration ( $5 \mathrm{mmol} / \mathrm{l}$ ) was tolerated by ATII cells, but not fibroblasts, and $25 \mathrm{mmol} / \mathrm{l}$ was not tolerated by either cell-type, where pronounced cell death was noted (data not shown). This caffeine range for cell viability is in line with the reports of others documenting safe doses of caffeine up to $1 \mathrm{mmol} / \mathrm{l}$ for fibroblasts and epithelial cells $(9,23)$. Caffeine administration increased mRNA expression of the type I TGF- $\beta$ receptor (TGF $\beta R 1$, Tgfbr 1; Figure 1a) and the TGF $\beta 3$ ligand (Tgfb3; Supplementary Figure S1 online) in mouse lung fibroblasts. Additionally, caffeine down-regulated protein expression of TGF $\beta$ R3 (Tgfbr3, betaglycan), and, in contrast to the gene expression trends, the protein abundance of total Smad2 and TGF $\beta$ R1 was reduced (Figure $1 \mathbf{b}$; quantified in Supplementary Figure S2a-c online). Stimulation of primary mouse lung fibroblasts with TGF $\beta 1$ ligand $(10 \mathrm{ng} / \mathrm{ml})$ increased connective tissue growth factor (CTGF; Figure 1c) and plasminogen-activator inhibitor (PAI)-1 (Figure 1d) expression. Caffeine potentiated the impact of TGF $\beta 1$ ligand on CTGF (Figure 1c) and PAI-1 (Figure 1d) expression. Consistent with the data presented in Figure $\mathbf{1 b}$, caffeine reduced total Smad2 protein levels, and also reduced stimulated phospho-Smad2 levels (Figure 1e). However, the ratio of phospho-to-total-Smad 2 was increased after TGF- $\beta$ stimulation comparing $\mathrm{NaCl}$ - vs. caffeine-treated cells, when blots were assessed by densitometry, suggesting hyper-phosphorylation of Smad2 (Supplementary Figure S3a online). In ATII cells, caffeine administration also upregulated TGF $\beta$ R1 mRNA expression (Figure 1f), similar to what was noted in fibroblasts (Figure 1a), and upregulated Smad3 and Smad7 mRNA levels. Also consistent with the impact of caffeine on fibroblasts, in ATII cells, caffeine reduced the abundance of TGF $\beta R 3$, total Smad2 and TGF $\beta$ R1 (Figure 1g; quantified in Supplementary Figure S2d-f online). In ATII cells, CTGF (Figure 1h), but not PAI-1 (Figure 1i) was TGF- $\beta$-responsive. Consistent with observations made in fibroblasts, caffeine potentiated the ability of TGF- $\beta$ to drive CTGF gene expression (Figure 1h). Caffeine reduced Smad2 protein abundance in ATII cells, without impacting phospho-Smad2 levels, again suggesting that Smad2 was hyper-phosphorylated in TGF- $\beta$ stimulated ATII cells treated with caffeine (Figure $1 \mathbf{j}$; quantified in Supplementary Figure S3b online).

\section{Administration of Caffeine to Newborn Mice}

The study protocol for the administration of caffeine in the hyperoxia-based mouse model of BPD is presented in Figure 2a. Within $1 \mathrm{~h}$ of caffeine administration $(25 \mathrm{mg} / \mathrm{kg}$ in $\mathrm{NaCl}$, via i.p. injection), caffeine could be detected in the lungs of mouse pups ( $2.04 \pm 0.16 \mu \mathrm{g} /$ lung; Figure $2 \mathrm{~b})$ by high performance liquid chromatography. This level remained stable after a further $1 \mathrm{~h}$ (Figure 2b). No caffeine was detected in the lungs of mouse pups that received $\mathrm{NaCl}$ vehicle alone. Similarly, no caffeine was detected in the lungs of mouse pups $24 \mathrm{~h}$ after caffeine administration. At $2 \mathrm{~h}$ postcaffeine administration, an increased respiratory rate was noted in pups, compared with pups that did not receive caffeine (Supplementary Video 1 online). By postnatal day (P)14, caffeine administration had normalized the body mass in hyperoxia-exposed mouse pups treated with caffeine $(5.46 \pm 0.47 \mathrm{~g})$, compared with normoxia-exposed mouse pups that received $\mathrm{NaCl}$ vehicle alone $(5.34 \pm 0.27 \mathrm{~g} ; P=0.87$ compared with the hyperoxia+caffeine group; Figure 2c). 


\section{Articles $\mid$ Rathetal.}

Table 2. Structural parameters of developing mouse lungs treated daily with caffeine or $\mathrm{NaCl}$ during exposure to $21 \% \mathrm{O}_{2}$ or $85 \% \mathrm{O}_{2}$ assessed by stereological analysis

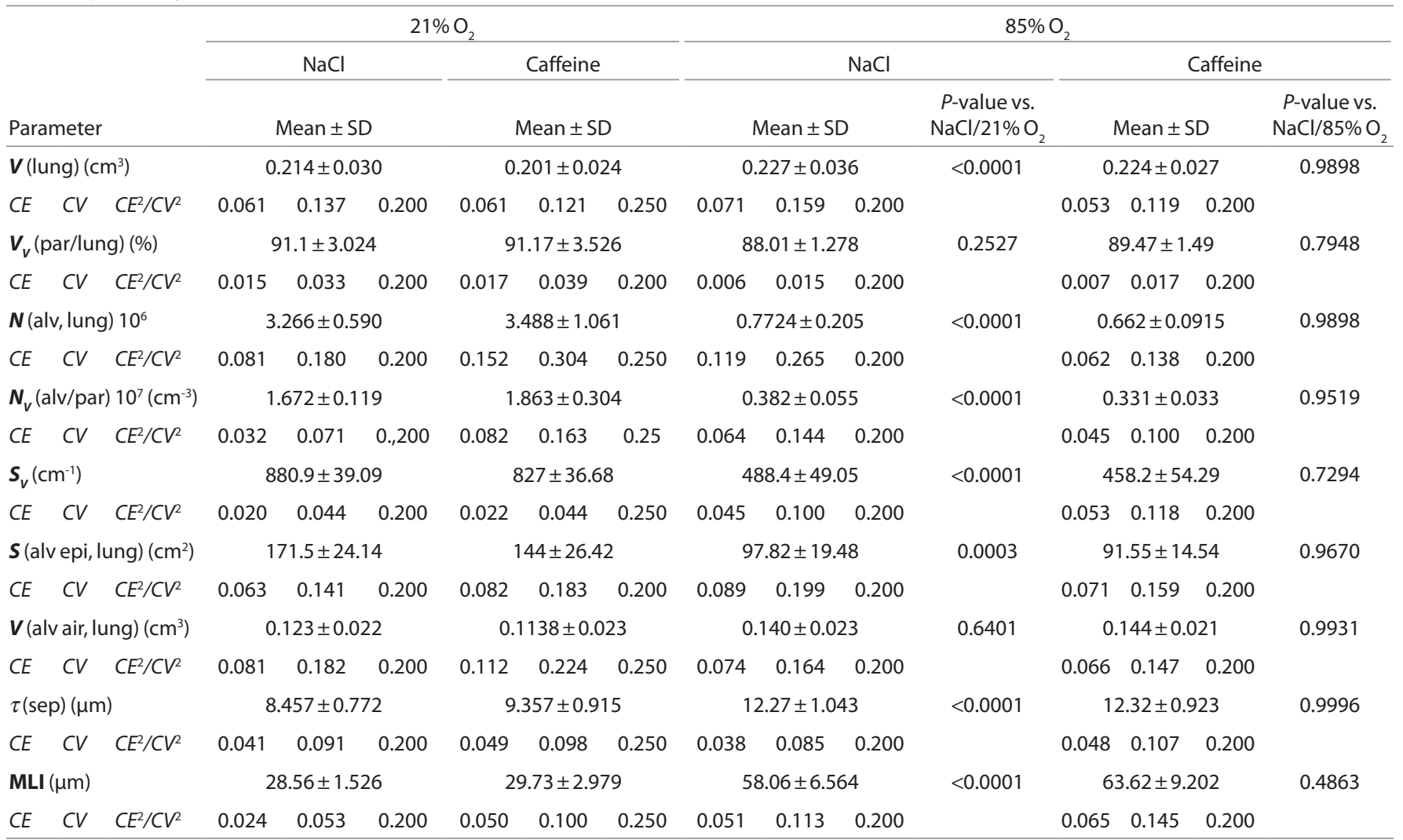

alv, alveoli; alv air, alveolar airspaces; alv epi, alveolar epithelium; $C V$, coefficient of variation; $C E$, coefficient of error; MLI, mean linear intercept; $N$, number, $N$, numerical density; par, parenchyma; $S$, surface area; $S_{v^{\prime}}$ surface density; $\tau$ (sep), arithmetic mean septal thickness; $V$, volume; $V_{v^{\prime}}$ volume density; $V$ alues are presented as mean $\pm S D, n=5$ lungs per group. Oneway ANOVA with Tukey's post-hoc analysis.

\section{Impact of Caffeine on Lung Structure in Hyperoxia-arrested} Lung Alveolarization

Exposure of newborn mouse pups to hyperoxia $\left(85 \% \mathrm{O}_{2}\right)$ blunted postnatal lung maturation, as was evident by alveolar simplification (compare Figure 3a,b with Figure 3e,f; quantified in Table 2). Analysis of lung structure in the experimental groups by design-based stereology supported this idea, where a decrease in alveolar number (Figure 3i), alveolar density (Figure 3j), gas exchange surface area (Figure 3k), stereologically-determined mean linear intercept (a surrogate of alveolar size; Figure 31), and an increase in septal wall thickness (Figure 3m) were noted, although no change in lung volume was assessed (Figure 3n). Caffeine administration had no impact on normally-developing mouse lungs (Figure 3c,d). Similarly, caffeine administration during the hyperoxia exposure protocol had no impact on the blunted alveolarization of hyperoxia-exposed lungs (compare Figure 3e,f with Figure 3g,h). This assessment was validated by stereological analysis of caffeine-treated lungs (Figure 3i-m).

\section{Impact of Caffeine on TGF- $\beta$ Signaling in Hyperoxia-arrested Lung Alveolarization}

The mRNA expression of TGF $\beta R 1$ and TGF $\beta R 2$ in the lung was increased by hyperoxia, while that of TGF $\beta$ R3 was decreased (Figure 4a-c). Similarly, the mRNA abundance for all three
TGF $\beta$ ligands, TGF $\beta 1$, TGF $\beta 2$, and TGF $\beta 3$ (Figure $4 d-f$ ) and the second messengers Smad2, Smad3 (Figure 4g,h), and the inhibitory Smad, Smad7 (Figure 4i) was increased. Some of these changes, for example, for TGF $\beta$ R3, were paralleled at the protein expression levels, assessed by immunoblot (Figure 4j). In homogenates of lungs from normoxia-exposed mice, caffeine appeared to reduce the phosphorylation of Smad2 (Figure 4j, compare lanes 1-3 with lanes 4-6), while under hyperoxic conditions, caffeine promoted increased phosphorylation of Smad2 (Figure 4j, compared lanes 7-9 with lanes 10-12). While hyperoxia exposure increased the expression of the CTGF (Figure 5a) and PAI-1 (Figure 5b) reporters of distal TGF- $\beta$ signaling, caffeine administration did not further increase the expression of either gene, in the background of hyperoxia.

\section{DISCUSSION}

Caffeine is widely employed for the management of apnea of prematurity, and has performed remarkably well in reducing the incidence of, and long-term neurological sequelae of BPD, as well as facilitating extubation $(4-7,24,25)$. Given the positive performance of caffeine in managing patients with or at risk for $\mathrm{BPD}$, there is much interest in understanding whether caffeine influences the course of postnatal lung maturation, 


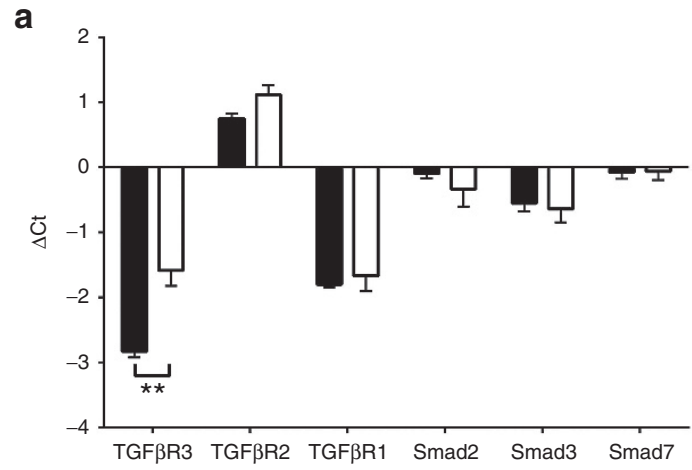

b

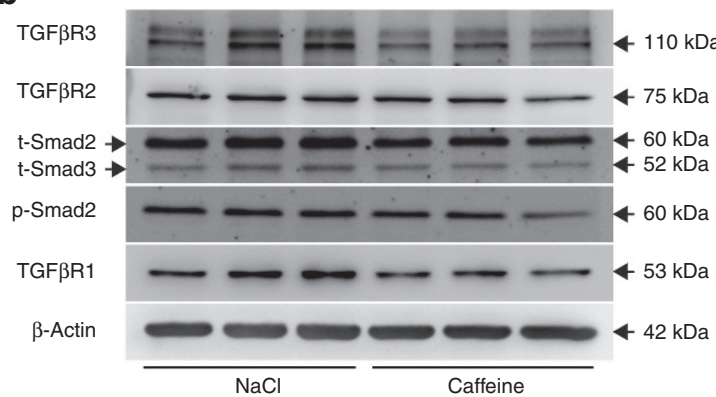

C

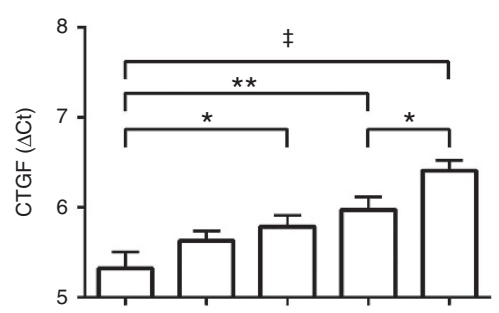

d

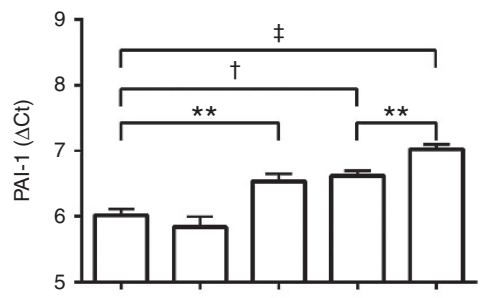

e

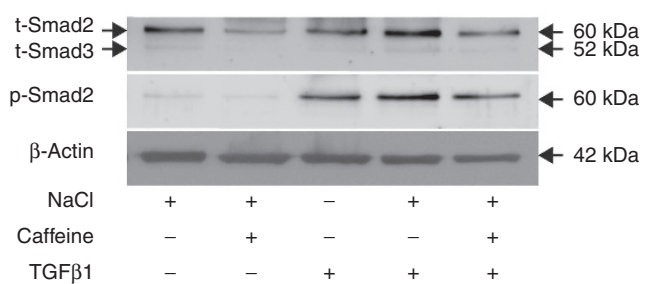

f

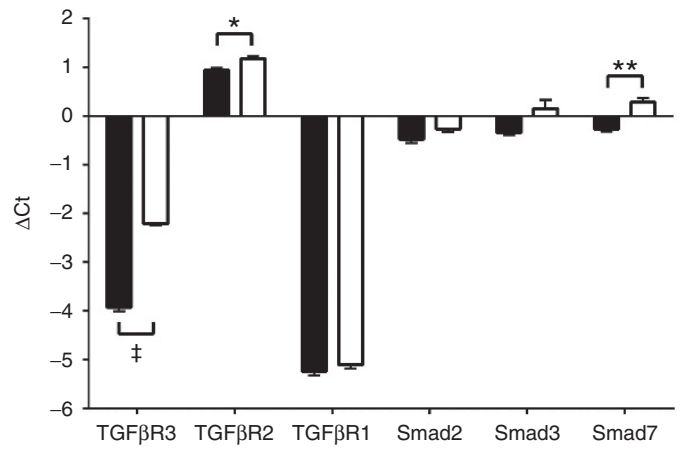

g

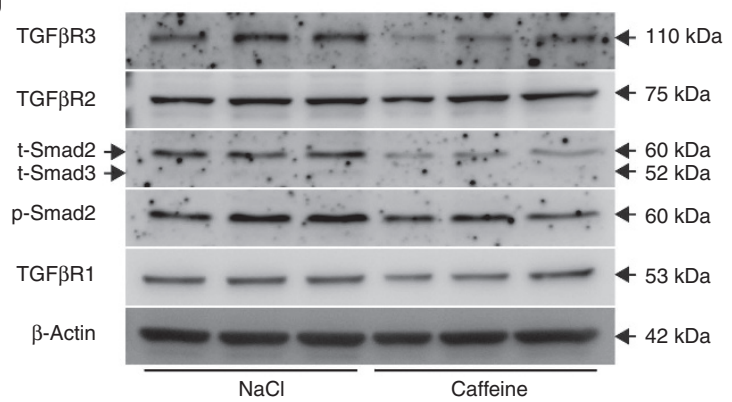

h

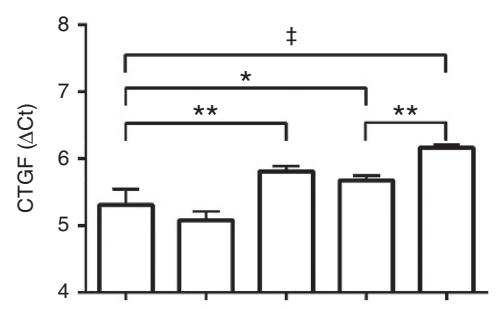

i

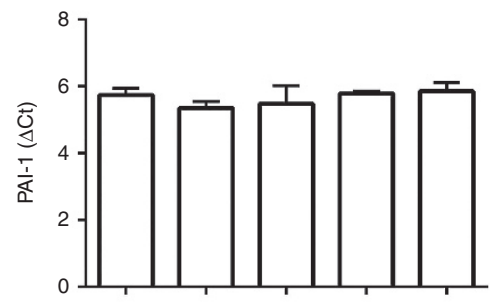

j

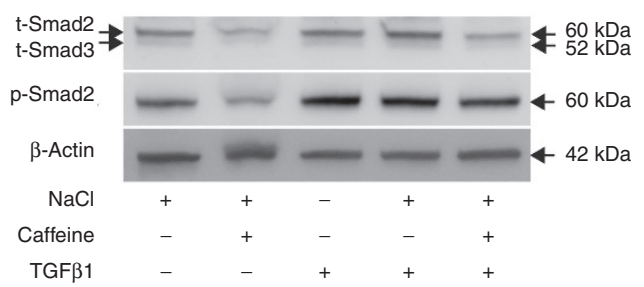

Figure 1. Effect of caffeine on baseline transforming growth factor (TGF)- $\beta$ signaling in primary mouse lung cells. Primary mouse lung fibroblasts (a-e) and alveolar type II cells (f-j) were treated with caffeine ( $1 \mathrm{mmol} / \mathrm{l}$ (open bars); in $\mathrm{NaCl}$ vehicle; or $\mathrm{NaCl}$ vehicle alone (closed bars)) for $48 \mathrm{~h}$. The gene $\mathbf{a}, \mathbf{f}$ and protein expression $\mathbf{b}, \mathbf{g}$ of components of the TGF- $\beta$ signaling machinery were assessed by real-time RT-PCR and immunoblot, respectively. The impact of caffeine pretreatment ( $1 \mathrm{mmol} / \mathrm{l}, 48 \mathrm{~h}$ ) on distal $\mathbf{c}, \mathbf{d}$; $\mathbf{h}, \mathbf{i}$ and proximal e,j TGF- $\beta$ signaling (after stimulation with $10 \mathrm{ng} / \mathrm{ml}$ TGF $\beta 1$ for $30 \mathrm{~min}$ ) was assessed using gene expression of connective tissue growth factor (CTGF) and plasminogen-activator inhibitor (PAI)-1 as distal reporters; and phosphorylation of Smad2 as a proximal reporter. Gene expression changes are indicated by $\Delta \mathrm{Ct} \pm \mathrm{SD}(n=3$, per group; each $n$ prepared in duplicate), using the Polr2a gene as reference. For immunoblots, $\beta$-Actin served as a control for loading equivalence. Trends observed by immunoblot are representative of trends noted in at least two other independent experiments. Two-group comparison a,f were evaluated by unpaired Student's $t$-test; while multigroup comparisons $\mathbf{c}, \mathbf{d}$ and $\mathbf{h}$, $\mathbf{i}$ were evaluated by one-way ANOVA with Tukey's post-hoc test. ${ }^{*} P<0.05,{ }^{* *} P<0.01,{ }^{+} P<0.001,{ }^{\ddagger} P<0.0001$. t-Smad, total Smad; p-Smad, phospho-Smad. 


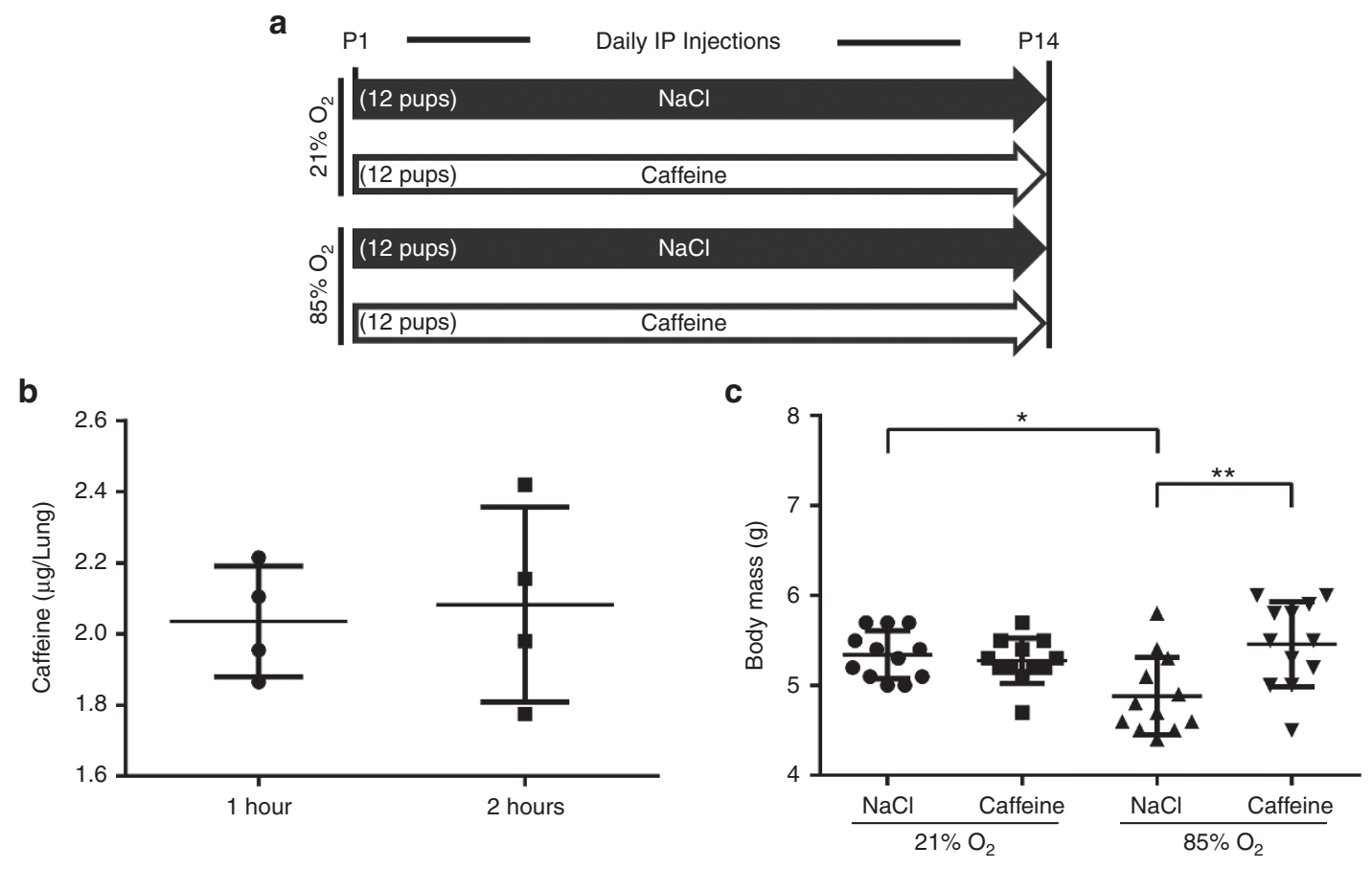

Figure 2. Caffeine administration to mouse pups. (a) Schematic illustration of study design. Mice were randomized on the day of birth (postnatal day (P)1) into four groups ( $n=12$ pups per group): Two groups were maintained under room air conditions $\left(21 \% \mathrm{O}_{2}\right.$ in the inspired air), while the other two groups were maintained under hyperoxic conditions $\left(85 \% \mathrm{O}_{2}\right.$ in the inspired air). For each oxygen concentration, one group receiving a daily IP injection of vehicle $(\mathrm{NaCl})$ alone, while the partner group received daily IP injection of caffeine $(25 \mathrm{mg} / \mathrm{kg} / \mathrm{d})$. (b) Caffeine delivery to the mouse lung was validated by random sampling of pup groups, $1 \mathrm{~h}$ or $2 \mathrm{~h}$ postadministration, where lungs were harvested and processed for quantitative determination of caffeine by high performance liquid chromatography. Each data point reflects an individual animal. No difference in the caffeine content of the lungs in the two groups was noted, when data were compared by unpaired Student's $t$-test. Caffeine was not detected in the lungs harvested from control (NaCl-treated) mice (data not shown). (c) The impact of caffeine on body masses determined on day 14 is illustrated. Data reflect mean body mass \pm SD $(n=12$, per group). Changes in body mass between the experimental groups were evaluated by one-way ANOVA with Tukey's post-hoc test. ${ }^{*} P<0.05,{ }^{* *} P<0.01$.

which is severely blunted in BPD patients. Caffeine impacts pulmonary inflammation (11), growth factor signaling (13), and cell death (10), which are pathogenic contributors to arrested alveolarization in BPD (8). However, the current literature presents a confusing picture of whether, and how, caffeine influences alveolarization in experimental animal models of BPD. Clearly, the primary mechanism by which caffeine reduces BPD is by reducing apnea and improving respiratory drive, thereby reducing ventilation-induced lung injury (5). However, it remains of interest to assess whether caffeine administration might directly impact lung development per se.

We examined the impact of caffeine on TGF- $\beta$ signaling in the lung, since TGF- $\beta$ signaling is critical for lung alveolarization (26-28), and deregulated TGF- $\beta$ signaling is associated with alveolar simplification in mice in response to both hypoxia (29) and hyperoxia $(16,30,31)$, in experimental models of BPD. Furthermore, caffeine impacts TGF- $\beta$ signaling in lung-derived cell-lines (13). We noted an impact of caffeine on the expression of the TGF- $\beta$ signaling machinery, where caffeine downregulated the protein expression of two TGF- $\beta$ receptors, Tgfbr1 and Tgfbr3, and the second messenger Smad2 in both primary lung fibroblasts and ATII cells. Using CTGF and PAI- 1 as reporters of distal TGF- $\beta$ signaling, caffeine potentiated TGF- $\beta$ signaling in both primary lung cell types, possible due to the hyper-phosphorylation of the remaining (smaller) cellular pools of Smad2, or due to the downregulated expression Tgfbr3, which antagonizes TGF- $\beta$ signaling. Taken together, our data indicate that caffeine does modulate TGF- $\beta$ signaling in primary lung cells in vitro. Given the critical role played by TGF- $\beta$ signaling in normal and aberrant alveolarization, we reasoned that caffeine administration in an animal model of BPD may alter the course of aberrant alveolarization provoked by hyperoxia exposure. This idea was reinforced by the knowledge that TGF- $\beta$ signaling mediatesat least in part-the aberrant alveolarization noted in experimental animal models of BPD.

To address this idea, we applied a state-of-the-art designbased stereology approach to study the structure of the developing mouse lung in a hyperoxia-based model of BPD, a well-characterized model of BPD that relies on the exposure of newborn mouse pups to elevated oxygen levels in the inspired air. This model has recently been reviewed extensively $(8,32)$. The hyperoxia-based models are believed to recapitulate the lung pathophysiological hallmarks of "new" BPD; which includes alveolar simplification and increased septal wall thickness; however, these perturbations to lung structure occur in the absence of baro- and volu-trauma from mechanical ventilation, and without any impact of infection or infection-driven inflammation, which represent limitations of the model. Thus, the hyperoxia-based mouse models are believed 

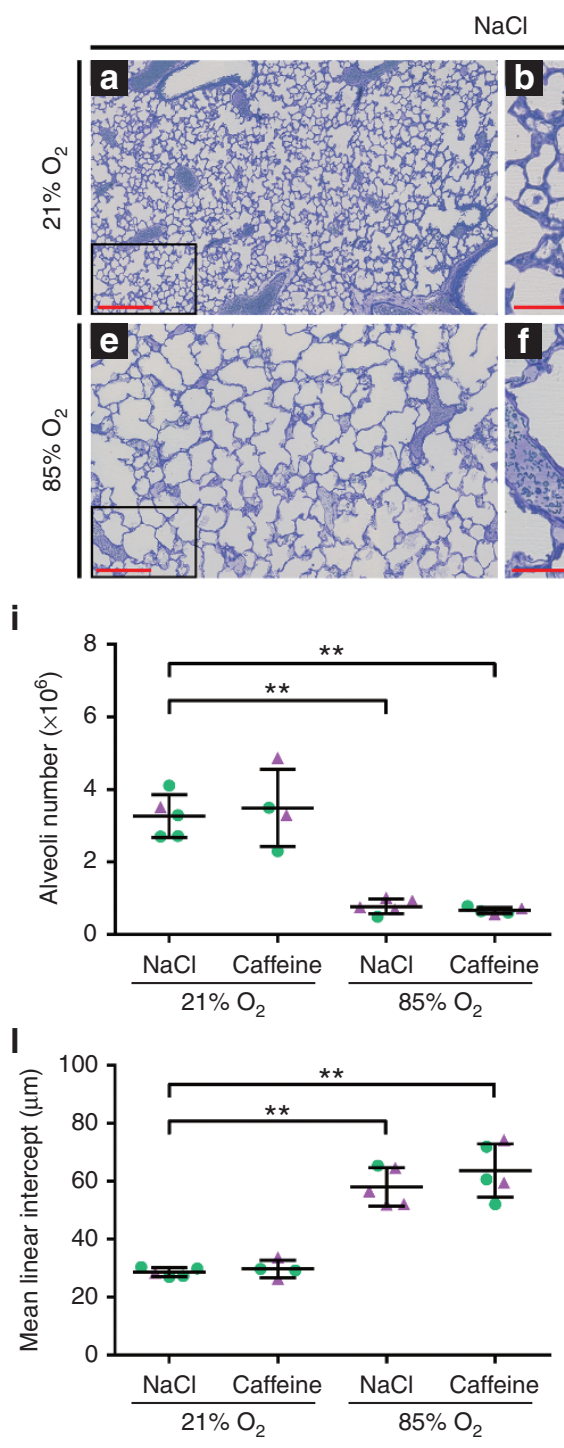

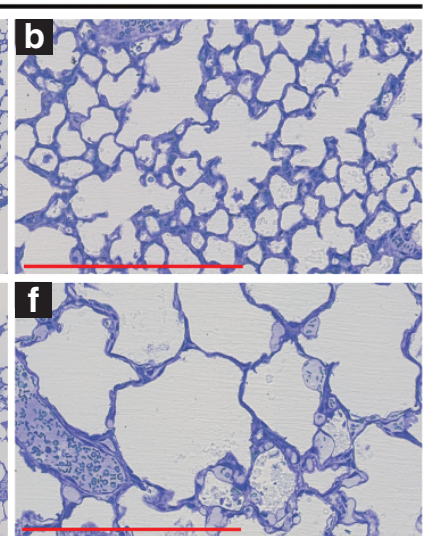

j

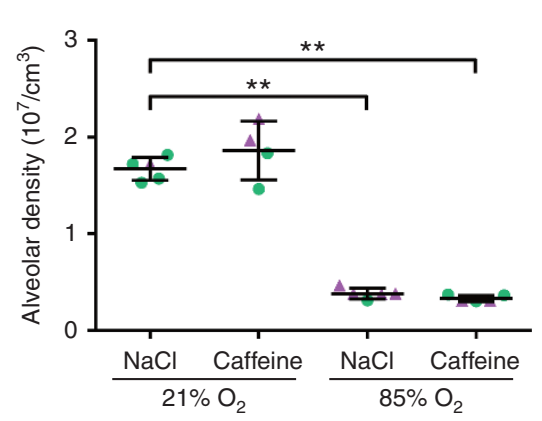

m

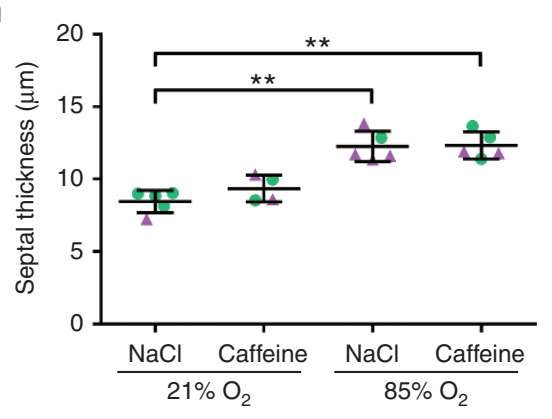

Caffeine

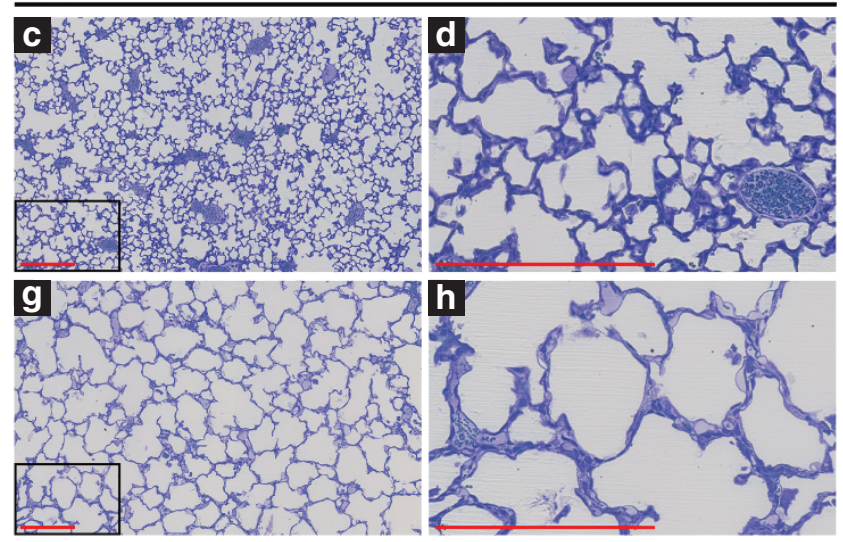

$\mathbf{k}$

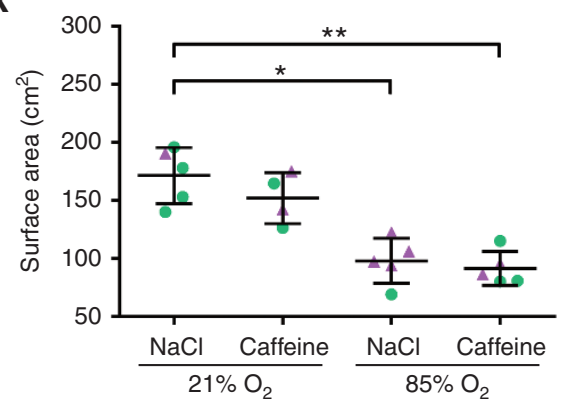

n

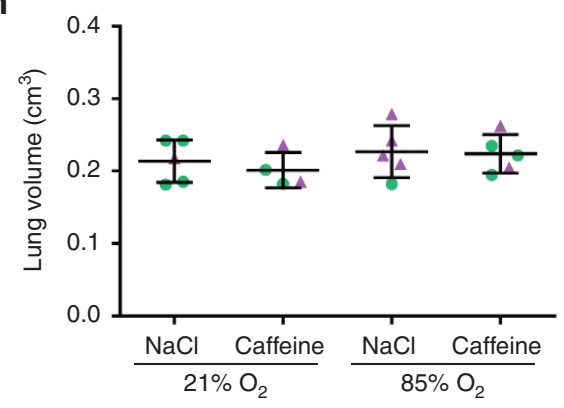

Figure 3. Stereological analysis of lung structure after caffeine administration. (a-h) Representative microscopic images of lungs from each experimental group, stained with Richardson's stain. Scale bar $=200 \mu \mathrm{m}$. For each experimental group, a low-power magnification is depicted, and a high-power magnification of the region demarcated in the black box is presented to the right of the respective image. Stereological analysis of the groups permitted quantification of (i) alveoli number, (j) alveolar density, (k) gas exchange surface area, (I) the stereologically-determined mean linear intercept, (m) mean septal wall thickness. Additionally, (n) the lung volume was determined by the Cavalieri principle. Data reflect mean \pm SD $(n=4-5$, per group). Experimental groups were compared by one-way ANOVA with Tukey's post-hoc test. ${ }^{*} P<0.001$, ${ }^{* *} P<0.0001$. Closed green circles represent male animals, while closed magenta triangles represent female animals.

to capture a particular part of the pathophysiological picture, namely, hyperoxia-mediated arrest of secondary septation.

While alveolar development was clearly impacted by exposure of newborn mouse pups to hyperoxia, as is evident by a dramatically reduced number of alveoli and a thickened septal wall, caffeine administration at a dose of $25 \mathrm{mg} / \mathrm{kg} / \mathrm{d}$ for the first $14 \mathrm{~d}$ of life neither improved nor worsened alveolar development. Ours is the first report to demonstrate that caffeine administered via the i.p. route did rapidly (within $1 \mathrm{~h}$ ) reach the lungs of mouse pups. Furthermore, this was accompanied by immediate physiological consequences (the increased respiratory rate evident in Supplementary Video 1 online). Some beneficial effects of caffeine administration were noted, such as the normalization of body mass, which in hyperoxia-exposed mouse pups that received caffeine was equivalent to the body mass of normoxia-exposed mouse pups that received vehicle alone (i.e., body mass was normal). A broad screen of lung homogenates from these animals revealed that both hyperoxia and caffeine administration did influence the expression and activity of the TGF- $\beta$ system in the lung. However, due to the loss of compartmentalization in lung homogenates, it was not possible to attribute these changes to a particular cell type. These data indicate that while caffeine could impact TGF- $\beta$ signaling in the developing lung, the ability of caffeine to modulate TGF- $\beta$ signaling could not limit or reverse the injurious effects of hyperoxia on lung alveolarization.

Interestingly, our findings contrast with those of Dayamin et al. (10), who reported that administration of caffeine in a 


\section{Articles $\mid$ Rath et al.}

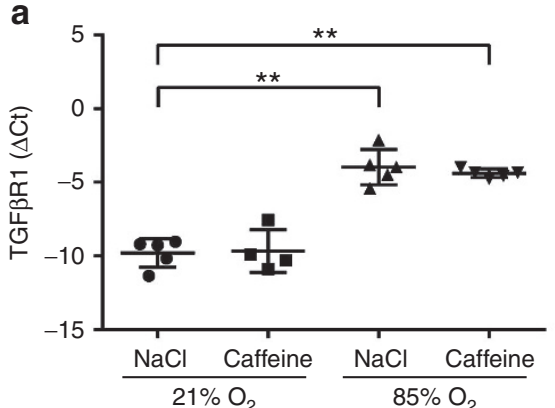

d

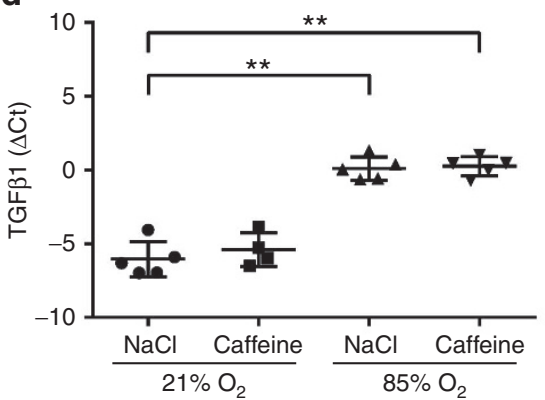

g

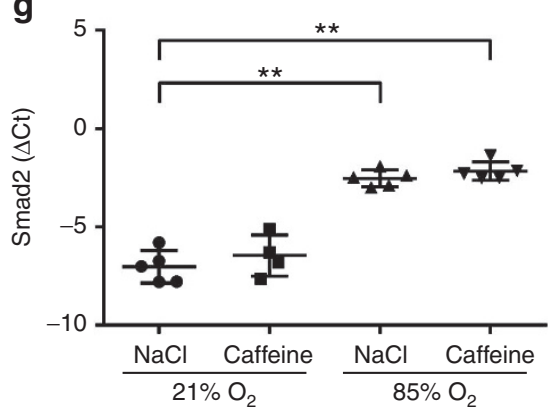

b

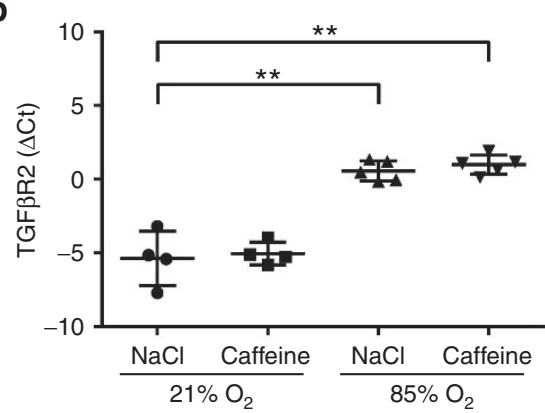

e

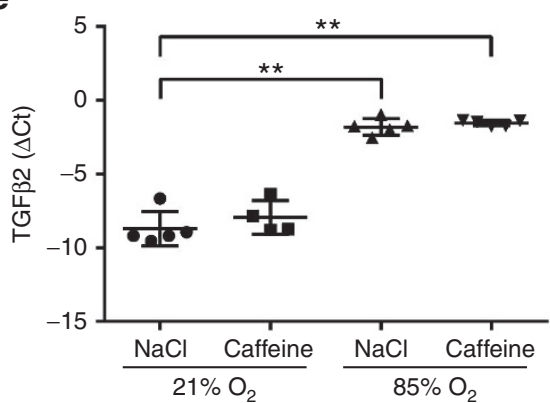

h

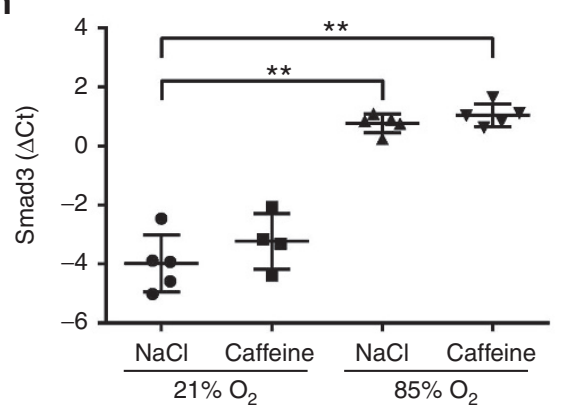

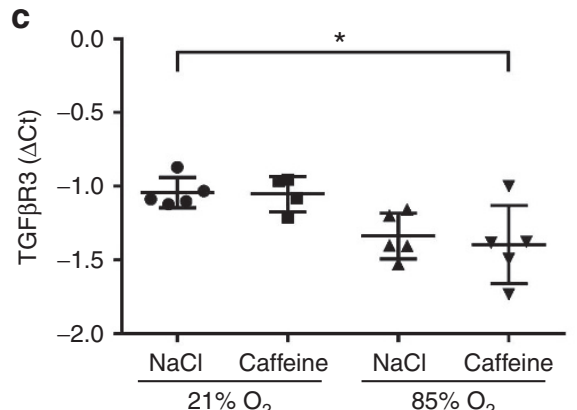

f

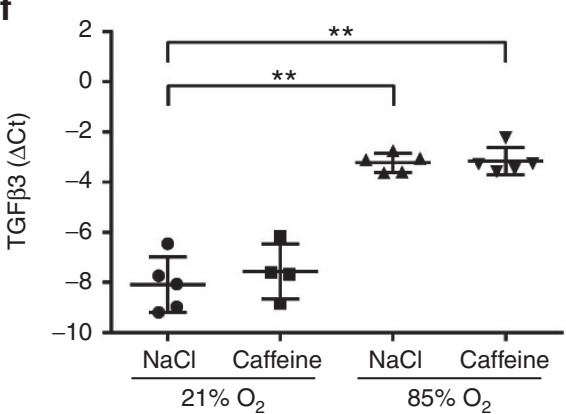

i

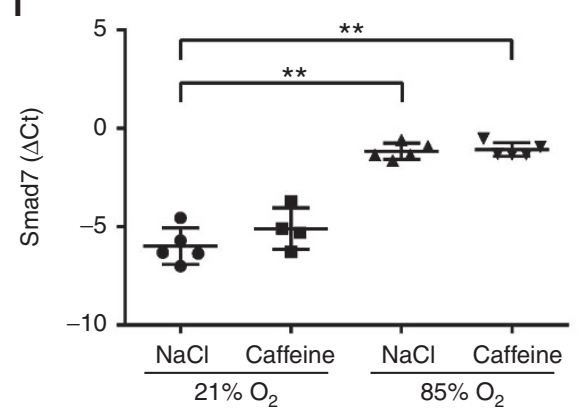

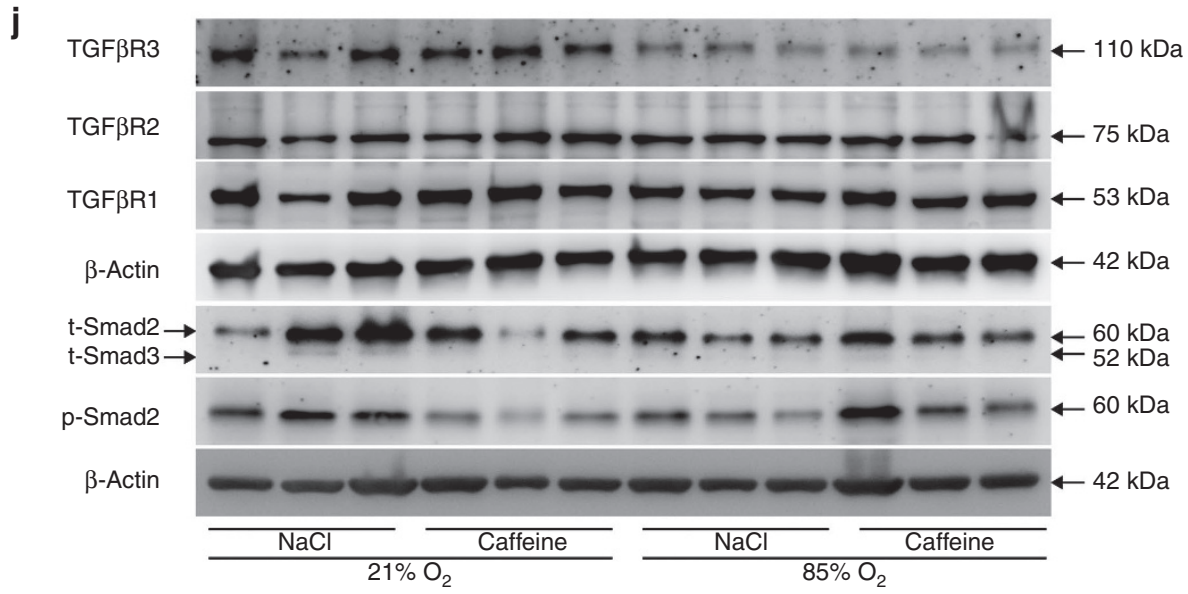

Figure 4. Effect of caffeine on baseline transforming growth factor (TGF)- $\beta$ signaling in lungs from caffeine-treated mouse pups. The gene (a-i) and protein expression (j) of components of the TGF- $\beta$ signaling machinery were assessed by real-time RT-PCR and immunoblot, respectively. Gene expression changes are indicated by $\Delta \mathrm{Ct} \pm \mathrm{SD}(n=4-5$, per group; each $n$ prepared in duplicate), using the Polr2a gene as reference. For immunoblots, $\beta$-Actin served as a control for loading equivalence. Trends observed by immunoblot are representative of trends noted in at least two other independent experiments. Changes in gene expression were evaluated by one-way ANOVA with Tukey's post-hoc test. ${ }^{*} P<0.05,{ }^{* *} P<0.0001$. t-Smad, total Smad; $p$-Smad, phospho-Smad.

hyperoxia-based mouse BPD model worsened the structural development of the lung, where alveolar simplification was worsened by caffeine administration in the background of hyperoxia exposure, and pronounced loss of ATII cells, and alveolar epithelial cell apoptosis was noted. Although Dayamin et al., employed the same time-course (caffeine administration 

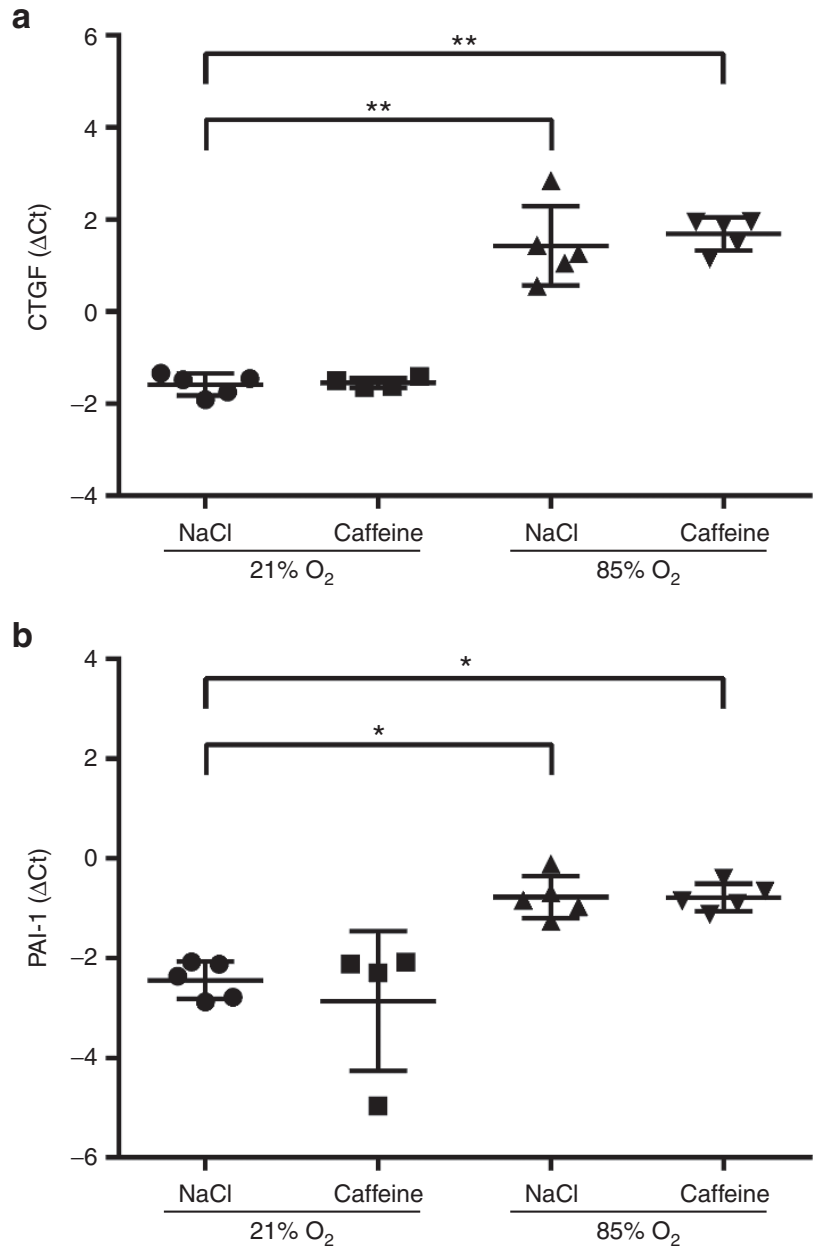

Figure 5. Effect of caffeine on transforming growth factor (TGF)- $\beta$ reporter gene expression in the lungs from caffeine-treated mouse pups. The expression of connective tissue growth factor (CTGF) and plasminogen-activator inhibitor (PAI)- 1 was employed as a distal reporter of TGF- $\beta$ signaling. Gene expression changes are indicated by $\Delta \mathrm{Ct} \pm \mathrm{SD}(n=4-5$, per group; each $n$ prepared in duplicate), using the Polr2a gene as reference. Changes in gene expression were evaluated by one-way ANOVA with Tukey's post-hoc test. ${ }^{*} P<0.05,{ }^{* *} P<0.0001$. t-Smad, total Smad; p-Smad, phospho-Smad.

and hyperoxia exposure for the first $14 \mathrm{~d}$ of postnatal life), Dayamin et al., administered a lower caffeine dose than we did $(20 \mathrm{mg} / \mathrm{kg}$ caffeine citrate on day 1 , followed by $10 \mathrm{mg} /$ $\mathrm{kg} / \mathrm{d}$ caffeine citrate thereafter). Given that caffeine citrate was administered, these doses translate to $10 \mathrm{mg} / \mathrm{kg}$ caffeine on day 1 , followed by $5 \mathrm{mg} / \mathrm{kg} / \mathrm{d}$ caffeine citrate thereafter, which are substantially lower than our $25 \mathrm{mg} / \mathrm{kg} / \mathrm{d}$, where pure caffeine was administered. Additionally, Dayamin et al. exposed mice to $80 \% \mathrm{O}_{2}$, while we employed $85 \% \mathrm{O}_{2}$. It is not immediately clear why the higher hyperoxic insult and fivefold higher dose of caffeine we employed was without any impact on lung development, in contrast to the gentler intervention of Dayamin et al. However, one important difference between the two studies was the strain of mouse employed, where we have used C57BL/6 mice, while Dayamin et al. employed FVB/n mice. These two mice strains are known to be differentially susceptible to pulmonary insult, where $\mathrm{FVB} / \mathrm{n}$ mice are more likely to develop spontaneous pneumonitis (33). It remains to be demonstrated whether different mouse strains exhibit different susceptibility to hyperoxia-induced arrest of lung alveolarization.

In addition to the clinical application of caffeine in preterm infants, caffeine has demonstrated much promise in animal models of BPD, where caffeine administration limited pulmonary inflammation provoked by hyperoxia (11), and improved lung alveolarization in preterm rabbits (12). In vitro and in vivo, caffeine did impact TGF- $\beta$ signaling, however, caffeine administration in the protocol employed here did not impact normal or aberrant alveolarization. As such, it must be concluded that the effects of caffeine on TGF- $\beta$ signaling were epiphenomenal, and play no functional role in modulating lung alveolarization. One reason why caffeine in our system may not have proved beneficial is the short biological half-life of caffeine, which is estimated to be $0.72 \mathrm{~h}$ in mice (compared with $2-8 \mathrm{~h}$ in human adults) (34).

In our protocol, caffeine was administered once every $24 \mathrm{~h}$, thus, assuming complete distribution over the first few hours of administration, caffeine would be rapidly lost from the lung, and indeed, the whole organism. As such, if any beneficial effects of caffeine on lung alveolarization required persistently elevated caffeine levels, these effects would be quickly lost after administration in the current dosing protocol. The caffeine doses employed in our study $(25 \mathrm{mg} / \mathrm{kg} / \mathrm{d})$ are at the high-end of caffeine dosing in experimental animal models of BPD (most studies employ $5-10 \mathrm{mg} / \mathrm{kg} / \mathrm{d}$ or less $(10-12)$ ), and exceed the caffeine dosing protocols employed in preterm infant in a NICU setting $(5,7)$, although this must be balanced with the increased half-life of caffeine in humans vs. mice, particularly in hospitalized preterm infants. The elimination of caffeine is substantially slower in preterm neonates $\left(t_{1 / 2}\right.$, $102.6 \mathrm{~h})$ vs. term neonates $\left(t_{1 / 2}, 80 \mathrm{~h}\right)$ vs. adults $\left(t_{1 / 2}, 0.6 \mathrm{~h}\right)(35)$, where the $t_{1 / 2}$ may be further prolonged by medical interventions such as gyrase inhibitors, which include the fluoroquinolones ciprofloxacin and nalidixic acid (36). This persistence of caffeine in hospitalized preterm infants has even led to caution that caffeine levels may not drop to subtherapeutic levels for 2 wk after hospital discharge (37). Thus, caffeine elimination is an important consideration in caffeine dosing in experimental settings. Nevertheless, the caffeine dose we employed remains far from the limit of caffeine dosing in experimental studies, where some protocols report administration of up to $80 \mathrm{mg} / \mathrm{kg} / \mathrm{d}$ in rats (38). Thus, we propose that sustained caffeine levels in developing lungs may have the capacity to promote improved alveolar growth under hyperoxia conditions; however, alternative dosing protocols should be examined. These protocols might include higher doses of caffeine (where toxicity may be a concern), or more regular dosing with more frequent parenteral administration or continuous application via a minipump. Concerns about local trauma from repeat i.p. injections in newborn mouse pups and the impracticability of minipump placement in newborn mouse pups probably precludes these two approaches, at least in the newborn mouse animal models of BPD at this time. Apart from increased dosing, further studies may consider more frequent injections by 
alternate routes (such as subcutaneous injection), or maternal transmission via breastmilk, which must be balanced against concerns of the pharmacokinetics of caffeine transmission via breast milk, and the health of the neonate, where caffeine consumption by nursing mothers is not recommended in a pediatric context $(39,40)$.

\section{SUPPLEMENTARY MATERIAL}

Supplementary material is linked to the online version of the paper at http:// www.nature.com/pr

\section{ACKNOWLEDGMENTS}

We thank Uta Eule and Nilifer Bouhya-Erdogan for the isolation of primary lung ATII cells and fibroblasts.

\section{STATEMENT OF FINANCIAL SUPPORT}

This study was supported by the Max Planck Society; Rhön Klinikum AG grant Fl_66; the Federal Ministry of Higher Education, Research and the Arts of the State of Hessen LOEWE Programm, the German Center for Lung Research, and by the German Research Foundation through Excellence Cluster 147, SFB1213, KFO309, and Mo 1789/1.

Disclosure: The authors have no conflicts of interest, financial or otherwise, to disclose.

\section{REFERENCES}

1. Vogl A. Euphylline. Wien Klin Wochenschr 1927;40:105

2. Kuzemko JA, Paala J. Apnoeic attacks in the newborn treated with aminophylline. Arch Dis Child 1973;48:404-6.

3. Henderson-Smart DJ, Steer PA. Caffeine versus theophylline for apnea in preterm infants. Cochrane Database Syst Rev 2010:CD000273.

4. Aranda JV, Gorman W, Bergsteinsson H, Gunn T. Efficacy of caffeine in treatment of apnea in the low-birth-weight infant. J Pediatr 1977;90:46772 .

5. Schmidt B, Roberts RS, Davis P, et al.; Caffeine for Apnea of Prematurity Trial Group. Caffeine therapy for apnea of prematurity. N Engl J Med 2006;354:2112-21.

6. Schmidt B, Roberts RS, Davis P, et al.; Caffeine for Apnea of Prematurity Trial Group. Long-term effects of caffeine therapy for apnea of prematurity. N Engl J Med 2007;357:1893-902.

7. Patel RM, Leong T, Carlton DP, Vyas-Read S. Early caffeine therapy and clinical outcomes in extremely preterm infants. J Perinatol 2013;33:13440.

8. Silva DM, Nardiello C, Pozarska A, Morty RE. Recent advances in the mechanisms of lung alveolarization and the pathogenesis of bronchopulmonary dysplasia. Am J Physiol Lung Cell Mol Physiol 2015;309:L123972 .

9. Tiwari KK, Chu C, Couroucli X, Moorthy B, Lingappan K. Differential concentration-specific effects of caffeine on cell viability, oxidative stress, and cell cycle in pulmonary oxygen toxicity in vitro. Biochem Biophys Res Commun 2014;450:1345-50.

10. Dayanim S, Lopez B, Maisonet TM, Grewal S, Londhe VA. Caffeine induces alveolar apoptosis in the hyperoxia-exposed developing mouse lung. Pediatr Res 2014;75:395-402.

11. Weichelt U, Cay R, Schmitz T, et al. Prevention of hyperoxia-mediated pulmonary inflammation in neonatal rats by caffeine. Eur Respir J 2013;41:966-73.

12. Nagatomo T, Jiménez J, Richter J, et al. Caffeine prevents hyperoxiainduced functional and structural lung damage in preterm rabbits. Neonatology 2016;109:274-81.

13. Fehrholz M, Speer CP, Kunzmann S. Caffeine and rolipram affect Smad signalling and TGF- $\beta 1$ stimulated CTGF and transgelin expression in lung epithelial cells. PLoS One 2014;9:e97357.

14. Madurga A, Mižíková I, Ruiz-Camp J, et al. Systemic hydrogen sulfide administration partially restores normal alveolarization in an experimental animal model of bronchopulmonary dysplasia. Am J Physiol Lung Cell Mol Physiol 2014;306:L684-97.
15. Mižíková I, Ruiz-Camp J, Steenbock H, et al. Collagen and elastin crosslinking is altered during aberrant late lung development associated with hyperoxia. Am J Physiol Lung Cell Mol Physiol 2015;308:L1145-58.

16. Alejandre-Alcázar MA, Kwapiszewska G, Reiss I, et al. Hyperoxia modulates TGF-beta/BMP signaling in a mouse model of bronchopulmonary dysplasia. Am J Physiol Lung Cell Mol Physiol 2007;292:L537-49.

17. Schwartze JT, Becker S, Sakkas E, et al. Glucocorticoids recruit Tgfbr 3 and Smad1 to shift transforming growth factor- $\beta$ signaling from the Tgfbr1/ Smad2/3 axis to the Acvrl1/Smad1 axis in lung fibroblasts. J Biol Chem 2014;289:3262-75.

18. Thomas L. Labor und diagnose: Indikation und Bewertung von Laborbefunden für die medizinische Diagnostik. 8. Auflage. Band 1. Frankfurt am Main: TH-Books Verlagsgesellschaft.

19. Hsia CC, Hyde DM, Ochs M, Weibel ER; ATS/ERS Joint Task Force on Quantitative Assessment of Lung Structure. An official research policy statement of the American Thoracic Society/European Respiratory Society: standards for quantitative assessment of lung structure. Am J Respir Crit Care Med 2010;181:394-418.

20. Madurga A, Golec A, Pozarska A, et al. The H2S-generating enzymes cystathionine $\beta$-synthase and cystathionine $\gamma$-lyase play a role in vascular development during normal lung alveolarization. Am J Physiol Lung Cell Mol Physiol 2015;309:L710-24.

21. Tschanz S, Schneider JP, Knudsen L. Design-based stereology: Planning, volumetry and sampling are crucial steps for a successful study. Ann Anat 2014;196:3-11.

22. Lambert JF, Benoit BO, Colvin GA, Carlson J, Delville Y, Quesenberry PJ. Quick sex determination of mouse fetuses. J Neurosci Methods 2000;95:127-32.

23. Bozchaloei SS, Gong SG, Dehpour AR, Farrokh P, Khoshayand MR, Oskoui M. Caffeine alters mitochondrial dehydrogenase and alkaline phosphatase activity of human gingival fibroblasts in vitro. J Investig Clin Dent 2013;4:233-9.

24. Henderson-Smart DJ, Davis PG. Prophylactic methylxanthines for endotracheal extubation in preterm infants. Cochrane Database Syst Rev 2010:CD000139.

25. Hütten MC, Wolfs TG, Kramer BW. Can the preterm lung recover from perinatal stress? Mol Cell Pediatr 2016;3:15.

26. Sureshbabu A, Syed MA, Boddupalli CS, et al. Conditional overexpression of TGF $\beta 1$ promotes pulmonary inflammation, apoptosis and mortality via TGF $\beta R 2$ in the developing mouse lung. Respir Res 2015;16:4.

27. Li A, Ma S, Smith SM, et al. Mesodermal ALK5 controls lung myofibroblast versus lipofibroblast cell fate. BMC Biol 2016;14:19.

28. McDevitt TM, Gonzales LW, Savani RC, Ballard PL. Role of endogenous TGF-beta in glucocorticoid-induced lung type II cell differentiation. Am J Physiol Lung Cell Mol Physiol 2007;292:L249-57.

29. Ambalavanan N, Nicola T, Hagood J, et al. Transforming growth factorbeta signaling mediates hypoxia-induced pulmonary arterial remodeling and inhibition of alveolar development in newborn mouse lung. Am J Physiol Lung Cell Mol Physiol 2008;295:L86-95.

30. Nakanishi H, Sugiura T, Streisand JB, Lonning SM, Roberts JD Jr. TGF-beta-neutralizing antibodies improve pulmonary alveologenesis and vasculogenesis in the injured newborn lung. Am J Physiol Lung Cell Mol Physiol 2007;293:L151-61.

31. Nardiello C, Morty RE. MicroRNA in late lung development and bronchopulmonary dysplasia: the need to demonstrate causality. Mol Cell Pediatr 2016;3:19.

32. Berger J, Bhandari V. Animal models of bronchopulmonary dysplasia. The term mouse models. Am J Physiol Lung Cell Mol Physiol 2014;307:L93647.

33. Schenkel AR, Chew TW, Chlipala E, Harbord MW, Muller WA. Different susceptibilities of PECAM-deficient mouse strains to spontaneous idiopathic pneumonitis. Exp Mol Pathol 2006;81:23-30.

34. Bonati M, Latini R, Tognoni G, Young JF, Garattini S. Interspecies comparison of in vivo caffeine pharmacokinetics in man, monkey, rabbit, rat, and mouse. Drug Metab Rev 1984;15:1355-83.

35. Aranda JV, Collinge JM, Zinman R, Watters G. Maturation of caffeine elimination in infancy. Arch Dis Child 1979;54:946-9. 


\section{Caffeine in experimental BPD}

36. Staib AH, Harder S, Mieke S, Beer C, Stille W, Shah P. Gyrase-inhibitors impair caffeine elimination in man. Methods Find Exp Clin Pharmacol 1987;9:193-8.

37. Doyle LW, Halliday HL, Ehrenkranz RA, Davis PG, Sinclair JC. An update on the impact of postnatal systemic corticosteroids on mortality and cerebral palsy in preterm infants: effect modification by risk of bronchopulmonary dysplasia. J Pediatr 2014;165:1258-60.
38. Tchekalarova JD, Kubová H, Mareš P. Early caffeine exposure: transient and long-term consequences on brain excitability. Brain Res Bull 2014;104:2735.

39. Liston J. Breastfeeding and the use of recreational drugs-alcohol, caffeine, nicotine and marijuana. Breastfeed Rev 1998;6:27-30.

40. Thorlton J, Ahmed A, Colby DA. Energy Drinks: Implications for the Breastfeeding Mother. MCN Am J Matern Child Nurs 2016;41:179-85. 